
\title{
25 Research Square \\ Folate Deficiency in Early Pregnancy Increases the Risk of Low Birth Weight: Survey of Neonates in Eastern China
}

\section{Yisheng Chen}

Obstetrics and Gynecology Hospital of Fudan University https://orcid.org/0000-0003-2116-2458

Chunmei Ying ( $\triangle$ ycmzh2012@163.com )

Obstetrics and Gynecology Hospital of Fudan University

\section{Research}

Keywords: folate, folic acid, low birth weight, pregnancy outcome, maternal nutrition, fetal metabolism, MTHFR C677T

Posted Date: February 25th, 2021

DOI: https://doi.org/10.21203/rs.3.rs-240879/v1

License: (c) (i) This work is licensed under a Creative Commons Attribution 4.0 International License.

Read Full License 


\section{Abstract}

Objective: Low birth weight (LBW) is a major cause of fetal mortality and morbidity. This study aims to assess the relationship between maternal serum folate levels and LBW in early pregnancy in eastern China.

Methods: We conducted a retrospective study including 124 newborns with LBW (born $\geq 1500 \mathrm{~g}$ to $<2500$ g) and 393 normal birth weight neonates (NBW). The maternal methylenetetrahydrofolate reductase (MTHFR) C677T polymorphism genotyping was performed by the gene chip hybrid method. The concentrations of serum homocysteine (hcy), folate, vitamin B12 and vitamin D were measured before 18 weeks of pregnancy. Multivariable logistic regression model was used to identify the predictors of LBW.

Results: After controlling the covariates, maternal underweight before pregnancy (AOR $=5.15: 95 \% \mathrm{Cl}$ $2.40,11.05)$, folate deficiency in early pregnancy $(A O R=2.06: 95 \% \mathrm{Cl} 1.03,4.09)$, preeclampsia during pregnancy $(A O R=6.02: 95 \% \mathrm{Cl} 2.83,12.81)$, and premature delivery $(A O R=23.81: 95 \% \mathrm{Cl} 12.90,43.95)$ were risk factors for $L B W$. However, multipara $(A O R=0.53: 95 \% \mathrm{Cl} 0.31,0.91)$ was a protective factor for LBW.

Conclusions: This study revealed different factors associated with LBW in eastern China. Sufficient folate before 18 weeks of pregnancy is a protective factor for LBW. Serum folate $>32.5 \mathrm{nmol} / \mathrm{L}$ can reduce the risk of LBW. Therefore, maternal screening of folate statue in the first trimester of pregnancy could be helpful.

\section{Introduction}

Low birth weight ( $L B W$, birth weighed $<2500 \mathrm{~g}$ ) is a global public health problem. The incidence of LBW is reported around $10 \%$ worldwide(1). And there are more than one million infants with LBW annually in China(2). Growing evidence have shown that newborns with LBW along with preterm birth (PTB, deliver within 37 weeks of gestation) are associated with fetal growth and neuronal development, increasing the risk of mortality and morbidity(2).

Folate is a micronutrient involved in one-carbon (1C) metabolism and supplies with methyl donors required for the DNA synthesis, repair and methylation, which is essential for fetal and placental growth(3, 4). Therefore, folate plays an important role during pregnancy. 5,10- methylenetetrahydrofolate reductase (MTHFR) is an essential regulator enzyme in the folate metabolism, which converts 5,10-MTHF to 5MTHF irreversible(5). Its C677T variants make the amino acid changed from alanine to valine, which results in a reduced enzymatic activity. Evidence by Frosst et al(6). showed that compared with MTHFR 677CC genotype, MTHFR 677 CT genotype retained nearly $65 \%$ of the enzymatic activity, and MTHFR 677 TT genotype retained only approximately $30 \%$. It was proved that the mutation of MTHFR C677T can lead to the decreasing of the folate utilization and hyper-homocysteinemia (HHcy)(7). Hcy is considered to damage the vascular endothelium, destroy the coagulation and fibrinolytic system, ultimately lead to adverse birth outcomes $(8,9)$. Statistics show folate deficiency is ubiquity in a quarter of pregnant women 
worldwide(10). Folate deficiency has been linked to neural tube defects (NTD) $(11,12)$, whereas its impact on other severe pregnancy outcomes is inconclusive. Some studies provide support to maternal MTHFR 677TT genotypes, together with maternal circulating folate and homocysteine (hcy) concentrations are independent risk factors for small gestational age (SGA)(13-15). Other observational studies found no direct association between low folate levels and pregnancy complications(16-18). To date, the role of folate intake to prevent NTD is verified $(19,20)$. Most relevant studies adopted self-statement of multivitamin supplementation, which may be imprecise, so serum folate concentration during pregnancy would be more ideal. Moreover, few studies focused on folate deficiency in early pregnancy in developing countries. In consideration of rural districts, folate deficiency was defined as $<6.8 \mathrm{nmol} / \mathrm{ml}$ and vitamin B12 deficiency as $<150 \mathrm{pmol} / \mathrm{ml}$, which are recommended by WHO(21). As majority of the women have multivitamin supplement during the first three-mouths pregnancy in urban area of China, the cut-offs of micronutrient (Vitamin B12 and folate) are inappropriate.

Given above elements, we collected a cohort of hospital-delivered neonates to explore the relationship between maternal folate status and LBW in eastern Chinese pregnant women before 18 weeks of gestation.

\section{Patients And Methods}

\section{Study population}

Hospital-delivered newborns were enrolled between April 2018 and October 2020 in the Obstetrics and Gynecology Hospital of Fudan University, including a total of 124 newborns with LBW and 393 NBW. Epidemiological data were collected for pregnant women covered maternal age at delivery $(<35, \geq 35$ years), pre-pregnancy body mass index (BMI), maternal education level (no education or primary education, secondary education, higher education), gravidity and parity.

The BMI was calculated by weight before pregnancy /(height ${ }^{2}$ ) and grouped into four categories according the China guidelines (underweight, <18.5, normal weight, 18.5-23.9, overweight, 24.0-27.9; obesity, $\geq 28.0$ ). Preeclampsia was defined as PRH (SBP $\geq 140 \mathrm{mmHg}$ or DBP $\geq 90 \mathrm{mmHg}$ ) with proteinuria ( $24 \mathrm{~h}$ urinary protein level of $>0.3 \mathrm{~g}$ or urine dipstick protein level $\geq+$ ). GDM was diagnosed by oral glucose tolerance test (fasting plasma glucose $\geq 5.1 \mathrm{mmol} / \mathrm{L}$, $1 \mathrm{~h}$ plasma glucose $\geq 10.0 \mathrm{mmol} / \mathrm{L}$, or $2 \mathrm{~h}$ plasma glucose $\geq 8.5 \mathrm{mmol} / \mathrm{L}$ ). The PTB was defined to deliver within 37 weeks of gestation. Gestational age of serum sampling was determined by the result of ultrasound. Serum biochemical parameters were measured within 18 weeks of gestation. Gestational age, delivery mode (eutocia vs. cesarean), gender and birth weight of newborns were obtained from medical records.

Pregnant women were excluded if they were under 18 years old, smoking or drinking, multiple pregnancy, embryo transfer, in vitro fertilization, and microbial infection. Neonates with birth defects, spontaneous abortion, birth weight $<1500 \mathrm{~g}$ or gestational age $<30$ weeks were also excluded in this study. 
Genomic DNA was extracted from the whole blood of the pregnant women using a column extraction kit. The MTHFR C677T polymorphism was detected by gene chip hybrid analysis following the manufacturer's instructions. The polymerase chain reaction (PCR), hybridization, gene array detection and analysis were conducted using the BaiO genotype detecting gene array kit and equipment (BaiO Technology Corp., Shanghai). The MTHFR C677T was genotyped as wild (CC), heterozygous (CT) and homozygous (TT) gene type, respectively.

\section{Measurement of biochemical parameters}

The biochemical parameters were measured before the 18th week of pregnancy. Plasma hcy was determined using Hitach 7600 automatic chemistry analyzer (Hitach Diagnostics Ltd.). Serum folate, vitamin B12 and vitamin D concentrations were measured using an Architect i2000 Analyzer (Abbott). The cut-off values for distribution of metabolic parameters considered in this study were hyper hcy $\geq 8 \mu \mathrm{mol} / \mathrm{L}$, folate deficiency $<32.5 \mathrm{nmol} / \mathrm{L}$, vitamin B12 deficiency $<280 \mathrm{pmol} / \mathrm{L}$, and vitamin $\mathrm{D}$ deficiency $<30 \mathrm{nmol} / \mathrm{L}$, respectively.

\section{Statistical analysis}

Statistical analyses were performed using the SPSS version 18.0 software (SPSS Inc., Chicago, IL, USA). Variable selection in multivariable modeling was based on clinical and statistical significance. Continuous variables were expressed as mean \pm standard deviation (SD) and categorical variables were indicated as number and percent $(n, \%)$. Independent-sample $t$ test or chi-square test was used to evaluate the difference in clinical characteristics. A two-sided $p$-value less than 0.05 was considered to be statistically significant. Multivariable logistic regression analysis was used to determine the adjusted odds ratios (AOR) with $95 \%$ confidence intervals $(\mathrm{Cl})$ for the associations between folate deficiency and LBW, adjusted for maternal age, pre-pregnancy BMI, MTHFR 677T, PE, delivery mode, parity, and gestational age.

\section{Results}

\section{Socio-demographic Characteristics}

A cord of 517 pregnant women with neonate were included. Of these, 23.98\% (124/517) were LBW babies. The baseline characteristics are summarized in Table 1. There was a large difference in birthweight between LBW $(2164.90 \pm 227.53 \mathrm{~g})$ and NBW $(3350.71 \pm 415.75 \mathrm{~g})$ neonates. Gestational ages were also lower in LBW newborns $(249.72 \pm 15.89)$ than NBW $(274.06 \pm 9.84)$. The proportion of underweight, MTHFR T allele, folate deficiency, primipara, cesarean and preeclampsia of LBW were higher than NBW group. No other differences in maternal or neonatal characteristics were observed, including maternal age $(p=0.674)$, education level $(p=0.937), \operatorname{GDM}(p=0.352)$ and gender $(p=0.094)$. Besides, there were no difference with the proportion of pregnant women being deficient in vitamin B12 $(23.4 \% \mathrm{Vs}$ $24.4 \%)$ and vitamin D (28.2\% Vs $21.6 \%)$ and HHcy (29.8\% Vs $25.7 \%)$. 
Table 1

Maternal clinical characteristics and neonatal birth data in LBW $(n=124)$ and NBW $(n=393)$ groups

\begin{tabular}{|c|c|c|c|c|}
\hline Predictor variables & Category of variables & $\begin{array}{l}\text { LBW } \\
(n / \%)\end{array}$ & NBW (n/\%) & $\begin{array}{l}p \\
\text { value }\end{array}$ \\
\hline \multirow[t]{2}{*}{ Maternal age (years) } & $<35$ & $92(74.2)$ & $284(72.3)$ & 0.674 \\
\hline & $\geq 35$ & $32(25.8)$ & $109(27.7)$ & \\
\hline \multirow{4}{*}{$\begin{array}{l}\text { Pre-pregnancy BMI } \\
\left(\mathrm{kg} / \mathrm{m}^{2}\right)\end{array}$} & underweight (<18.5) & 23(18.5) & $33(8.4)$ & 0.013 \\
\hline & normal weight (18.5-23.9) & 73(58.9) & $253(64.4)$ & \\
\hline & overweight (24-27.9) & $22(17.7)$ & 76(19.3) & \\
\hline & obesity ( $\geq 28$ ) & $6(4.8)$ & $31(7.9)$ & \\
\hline \multirow[t]{2}{*}{ Parity } & primipara & $67(54.0)$ & $158(40.2)$ & 0.007 \\
\hline & multipara & $57(46.0)$ & $235(59.8)$ & \\
\hline \multirow[t]{3}{*}{ Education level } & $\begin{array}{l}\text { no education or primary } \\
\text { education }\end{array}$ & $7(5.6 \%)$ & $19(4.8 \%)$ & 0.937 \\
\hline & secondary education & $33(26.6 \%)$ & $106(27.0 \%)$ & \\
\hline & higher education & $84(67.7 \%)$ & $268(68.2 \%)$ & \\
\hline \multirow[t]{2}{*}{ GDM } & yes & $22(17.7 \%)$ & $85(21.6 \%)$ & 0.352 \\
\hline & no & 102(82.3) & $308(78.4)$ & \\
\hline \multirow[t]{2}{*}{ Preeclampsia } & yes & $37(29.8 \%)$ & $28(7.1 \%)$ & 0.000 \\
\hline & no & $87(70.2)$ & $365(92.9)$ & \\
\hline \multirow[t]{2}{*}{ Gestational age (weeks) } & $<37$ & $75(60.5)$ & 28(7.1) & 0.000 \\
\hline & $\geq 37$ & $49(39.5)$ & $365(92.9)$ & \\
\hline MTHFR & $\mathrm{CC}$ & $29(23.4)$ & $115(29.3)$ & 0.045 \\
\hline \multicolumn{5}{|l|}{ С677T } \\
\hline & CT & $62(50.0)$ & $212(53.9)$ & \\
\hline & TT & $33(26.6)$ & $66(16.8)$ & \\
\hline \multirow[t]{2}{*}{$\operatorname{Hcy}(\mu \mathrm{mol} / \mathrm{L})$} & $<8$ & $87(70.2)$ & 292(74.3) & 0.364 \\
\hline & $\geq 8$ & $37(29.8)$ & $101(25.7)$ & \\
\hline \multirow[t]{2}{*}{ Folic acid (nmol/L) } & $<32.5$ & $29(23.4)$ & $50(12.7)$ & 0.004 \\
\hline & $\geq 32.5$ & $95(76.6)$ & $343(87.3)$ & \\
\hline
\end{tabular}




\begin{tabular}{|lllll|}
\hline $\begin{array}{l}\text { Vitamin B12 } \\
(\mu \mathrm{mol} / \mathrm{L})\end{array}$ & $<280$ & $29(23.4)$ & $96(24.4)$ & 0.814 \\
\hline Vitamin D (pmol/L) & $\geq 280$ & & & \\
\hline & $\geq 30$ & $95(76.6)$ & $297(75.6)$ & \\
\hline Sex of the newborn & boys & $35(28.2)$ & $85(21.6)$ & 0.129 \\
\hline & girls & $89(71.8)$ & $308(78.4)$ & \\
\hline Mode of delivery & eutocia & $54(43.5)$ & $205(52.2)$ & 0.094 \\
\hline & cesarean & $70(56.5)$ & $188(47.8)$ & \\
\hline Gestational age $($ weeks $)$ & preterm $(<37)$ & $49(39.5)$ & $219(56.0)$ & 0.001 \\
\hline & term $(\geq 37)$ & $75(60.5)$ & $174(44)$ & \\
\hline
\end{tabular}

BMI, body mass index; Hcy, homocysteine; MTHFR, methylenetetrahydrofolic acid reductase

\section{Interaction of MTHFR C677T genotypes with serum parameter levels}

Table 2 shows the interaction of MTHFR C677T gene polymorphism with serum hcy, folate, vitamin B12 and vitamin D concentrations. Hcy concentrations were significantly higher in individuals having 677T allele of MTHFR (7.0 $\mu \mathrm{mol} / \mathrm{L}$ (TT) vs $6.28 \mu \mathrm{mol} / \mathrm{L}(\mathrm{CC}), p=0.004)$, while folate levels were lower (36.56 $\mathrm{nmol} / \mathrm{L}$ vs $38.62 \mathrm{nmol} / \mathrm{L}, p=0.023)$. However, MTHFR 677 genotypes did not show impact on Vitamin B12 or $\mathrm{D}$ levels. This result showed certain genotypes have a close relationship with serum hcy or folate levels.

\section{Table 2}

Interaction of MTHFR 677 genotypes with hcy, folate, vitamin B12 and D biomarkers

\begin{tabular}{|lllll|}
\hline $\begin{array}{l}\text { MTHFR C677 } \\
\text { T genotype }\end{array}$ & $\begin{array}{l}\text { Hcy } \\
(\mu \mathrm{mol} / \mathrm{L})\end{array}$ & $\begin{array}{l}\text { Folate } \\
(\mathrm{nmol} / \mathrm{L})\end{array}$ & $\begin{array}{l}\text { Vitamin B12 } \\
(\mathrm{pmol} / \mathrm{L})\end{array}$ & $\begin{array}{l}\text { Vitamin D } \\
(\mathrm{nmol} / \mathrm{L})\end{array}$ \\
\hline CC & $6.28 \pm 1.51$ & $38.62 \pm 5.19$ & $405 \pm 159.52$ & $43.62 \pm 16.86$ \\
\hline CT & $6.70 \pm 1.86$ & $37.63 \pm 5.93$ & $385.88 \pm 145.02$ & $46.10 \pm 18.76$ \\
\hline TT & $7.00 \pm 1.53$ & $36.56 \pm 6.02$ & $364.76 \pm 149.01$ & $46.69 \pm 18.33$ \\
\hline$p$ value & 0.004 & 0.023 & 0.119 & 0.326 \\
\hline
\end{tabular}

Hcy, homocysteine; MTHFR, methylenetetrahydrofolic acid reductase 
After controlling the covariates, women with folate deficiency in early pregnancy had twice-higher odds of newborns with LBW compared to women with sufficient serum folate (AOR $=2.06: 95 \% \mathrm{Cl} 1.03,4.09$ ). The likelihood of LBW was 5 -folds higher odds among newborns who had underweight mothers before pregnancy compared to those normal weight mothers ( $A O R=5.15: 95 \% \mathrm{Cl} 2.40,11.05)$. As was expected, preterm births had 23-folds higher odds of LBW compared to full-term neonates (AOR $=23.81: 95 \% \mathrm{Cl}$ $12.9,43.95)$. Moreover, women who were diagnosed with preeclampsia during pregnancy had 6-greater odds of newborns with LBW (AOR $=6.02$ : $95 \% \mathrm{Cl} 2.83,12.81)$. While the odds of delivery with LBW babies were less by $47 \%$ among multipara women compared with primipara women (AOR $=0.53: 95 \% \mathrm{Cl} 0.31$, 0.91). Besides, maternal age, education level, GDM, hyper hcy, vitamin B12 or D deficiency, and gender were not associated with neonatal LBW in this study (Table 3).

Table 3

Multivariable logistic regression analysis for the risk factors associated with LBW

\begin{tabular}{|lllllll|}
\hline LBW & $\boldsymbol{\beta}$ & SE & Wald & df & P & AOR (95\% Cl) \\
\hline BMI & & & & & & \\
\hline underweight & 1.64 & 0.39 & 17.65 & 1 & 0.000 & $5.15(2.40-11.05)$ \\
\hline normal weight & & & & & & 1 (reference) \\
\hline overweight & -0.47 & 0.39 & 1.46 & 1 & 0.23 & $0.62(0.29-1.34)$ \\
\hline obesity & -1.14 & 0.61 & 3.46 & 1 & 0.06 & $0.32(0.10-1.06)$ \\
\hline MTHFR C677T & & & & & & \\
\hline CC & & & 2.56 & 2 & 0.28 & $1($ reference $)$ \\
\hline CT & -0.06 & 0.33 & 0.04 & 1 & 0.85 & $0.94(0.49-1.79)$ \\
\hline TT & 0.50 & 0.40 & 1.55 & 1 & 0.21 & $1.65(0.75-3.62)$ \\
\hline Folate deficiency & 0.72 & 0.35 & 4.21 & 1 & 0.04 & $2.06(1.03-4.09)$ \\
\hline Mode of delivery & -0.33 & 0.29 & 1.28 & 1 & 0.26 & $0.72(0.41-1.27)$ \\
\hline Preeclampsia & 1.80 & 0.39 & 21.67 & 1 & 0.000 & $6.02(2.83-12.81)$ \\
\hline Preterm & 3.17 & 0.31 & 102.78 & 1 & 0.000 & $23.81(12.90-43.95)$ \\
\hline Multipara & -0.64 & 0.28 & 5.25 & 1 & 0.022 & $0.53(0.31-0.91)$ \\
\hline
\end{tabular}

AOR, adjusted odds ratio; $\mathrm{Cl}$, confidence interval; BMI, body mass index; MTHFR, methylenetetrahydrofolic acid reductase

\section{Discussion}


According to epidemiological observations, LBW along with PTB remains the main cause of neonatal mortality and morbidity. Despite intervention efforts, the rate of LBW newborns remained high and varies across regions within countries(22-30), 9.8\% in USA and 13-17.3\% in Zimbabwe and Ethiopia(30-32). This study was conducted in eastern China where owned several Obstetrics and Gynecology Hospitals. The proportion of LBW was about $23.98 \%$ because we oversampled LBW at enrolment. As a result, the likelihood of delivering a LBW newborn would be less as compared to pregnant women in rural areas(26, 28).

A majority of studies principally emphasized the association of maternal folic acid supplementation and fetal birth weight(33-35). Our study focused on serum folate levels before 18 weeks of pregnancy and evaluated the relationship with LBW. In our individuals, serum folate concentrations were generally high, with a mean value of $37.71 \mathrm{nmol} / \mathrm{l}$. Beside the previously known factors (prematurity, preeclampsia)(36, $37)$, the results showed that folate deficiency $(<32.5 \mathrm{nmol} / \mathrm{l})$ before 18 weeks gestation was an independent risk factor for LBW in eastern Chinese pregnant women. This is more accurate than studying the relationship between folic acid supplementation and LBW. Similarly, our result indicated that the maternal preeclampsia in late pregnancy was found to be an independent factor contributing to LBW. The probability of LBW was 6 -folds higher among mothers having preeclampsia than those not having PE. This finding is in line with studies conducted in Ethiopia and $\operatorname{Nepal}(29,38)$. This might due to the decreased oxygen and nutrient perfusion to the placenta(30).

Our finding indicated that MTHFR 677T and folate deficiency were associated with LBW, not including vitamin B12 and D deficiency or elevated Hcy. Seemingly our findings were in disagreement with other results, which show that elevated Hcy and lowered folate levels during pregnancy are associated with LBW $(39,40)$. In fact, Hcy levels were significantly higher in individuals having 677T allele of MTHFR, while folate level was distinctly lower. However, following the binary logistic regression analysis, it turns out that folate deficiency but not MTHFR 677T was independent risk factor. This result might due to the different cut-off value of serum parameter levels. Here we define it as lower range of the parameter spectrum. Besides, no statistically significant difference was found in the education level of our individuals. However, a retrospective analysis of the Nigeria population found maternal characteristic (education) was a predictor of LBW, including a cohort of 9,244 live births(41). Another case-control study in Blacks and Whites reported maternal educational attainment was inversely associated with LBW overall, including 2,922 births to Black $(n=2,146)$ and White $(n=776)$ mothers $)(42)$. In this study, the rate of secondary school and higher education graduates were $94.97 \%$. We thought that the increased awareness of adequate multivitamin nutrition intake was associated with increased education levels. These two findings were contrary to our results, which may be due to the overall high level of education and low sample size of low education level pregnant women in our area.

It was reported that the risk of LBW in women with pre-pregnancy low BMI was significantly increased. One birth cohort survey of 3401 neonates in Pomerania found that compared to women with normal prepregnancy $\mathrm{BMI}$, underweight women had an increased chance of premature labour and low birth weight $(A O R=1.73 ; 95 \% \mathrm{Cl}: 1.29-2.31)(43)$. Our result was consistent with this phenomenon $(\mathrm{AOR}=5.15 ; 95 \% \mathrm{Cl}$ : 
2.40-11.05). In this research, we also found another interesting phenomenon. The likelihood of LBW was higher in primipara compared with multipara, suggesting multipara as a protective impact on LBW. This might be due to the fact that multipara women might have a better preparation folic acid supplementation and timely detection and treatment of folate statue. As a result, the likelihood of having a low birth weight baby would be less as compared to primipara. This finding supports that timely supervision, multivitamin supplement, and folate determination are important during early pregnancy.

There were several certain strengths and limitations in this study. We did not recruit babies with birth asphyxia or antenatal infection, delivery before 30 weeks gestation and/or $<1500 \mathrm{~g}$ birthweight. It allows us to confidently exclude any clinically severe conditions. In additions, the data were collected from medical records and avoided recall bias of self-report. In view of the fact that almost all mothers of our cases added folic acid or multivitamins, supplementation before pregnancy was not investigated, which could modify the level of plasma parameters. Further studies are warranted to examine other factors. The data was collected in eastern China so the results cannot generalizable to other zones.

\section{Conclusions}

Our study confirms a positive association between adequate serum folate concentrations before 18th pregnancy and increased birth weight. Based on our findings, maternal adequate folate status $(>32.5$ $\mathrm{nmol} / \mathrm{L}$ ) can reduce the risk of LBW. Further investigations with high-quality prospective data are required to explore the mechanisms. Clinicians should pay more attention to folate deficiency pregnant women and strengthen the supervision of early pregnancy, which has importance for newborn health.

\section{Abbreviations}

LBW: Low birth weight; NBW: normal birth weight neonates; MTHFR: methylenetetrahydrofolate reductase; Hcy: homocysteine; PTB: preterm birth; SGA: small gestational age; NTD: neural tube defects; BMI: body mass index; PCR: polymerase chain reaction; AOR: adjusted odds ratios; Cl: confidence interval

\section{Declarations}

\section{Acknowledgements}

We thank all the participants and researchers for their contributions to this study.

\section{Authors' Contributions}

All authors participated in the design, interpretation of the studies and analysis of the data and review of the manuscript. YC analyzed the data and wrote the manuscript, $Y Z$ revised the article, $C Y$ critically reviewed and modified the manuscript.

\section{Funding}


This work was supported by the National Nature Science Foundation of China (Grant 81873970).

\section{Availability of data and materials}

The data analyzed in the current study are available from the corresponding author on request.

\section{Ethics approval and consent to participate}

The current retrospective study protocol was approved by the Medicine Ethics Committee of Obstetrics and Gynecology Hospital of Fudan University (No. 2020-54). All women written informed consent in this study.

\section{Competing interests}

The author(s) declared no conflicts of interest with respect to the research, authorship, and/or publication of this article.

\section{References}

1. Frey HA, Klebanoff MA. The epidemiology, etiology, and costs of preterm birth. Semin Fetal Neonatal Med. 2016;21(2):68-73.

2. Blencowe $H$, Cousens $S$, Oestergaard MZ, Chou D, Moller AB, Narwal R, et al. National, regional, and worldwide estimates of preterm birth rates in the year 2010 with time trends since 1990 for selected countries: a systematic analysis and implications. Lancet. 2012;379(9832):2162-72.

3. Catalano PM, Shankar K. Obesity and pregnancy: mechanisms of short term and long term adverse consequences for mother and child. BMJ. 2017;356:j1.

4. Bailey LB, Stover PJ, McNulty H, Fenech MF, Gregory JF, 3rd, Mills JL, et al. Biomarkers of Nutrition for Development-Folate Review. J Nutr. 2015;145(7):1636S-80S.

5. Yamada K, Chen Z, Rozen R, Matthews RG. Effects of common polymorphisms on the properties of recombinant human methylenetetrahydrofolate reductase. Proc Natl Acad Sci U S A. 2001;98(26):14853-8.

6. Frosst P, Blom HJ, Milos R, Goyette P, Sheppard CA, Matthews RG, et al. A candidate genetic risk factor for vascular disease: a common mutation in methylenetetrahydrofolate reductase. Nat Genet. 1995;10(1):111-3.

7. Engbersen AM, Franken DG, Boers GH, Stevens EM, Trijbels FJ, Blom HJ. Thermolabile 5,10methylenetetrahydrofolate reductase as a cause of mild hyperhomocysteinemia. Am J Hum Genet. 1995;56(1):142-50.

8. Bennett M. Vitamin B12 deficiency, infertility and recurrent fetal loss. J Reprod Med. 2001;46(3):20912.

9. Nair RR, Khanna A, Singh R, Singh K. Association of maternal and fetal MTHFR A1298C polymorphism with the risk of pregnancy loss: a study of an Indian population and a meta-analysis. 
Fertil Steril. 2013;99(5):1311-8 e4.

10. Tinker S, Hamner H, Qi Y, Crider KJBdrPA, Clinical, teratology m. U.S. women of childbearing age who are at possible increased risk of a neural tube defect-affected pregnancy due to suboptimal red blood cell folate concentrations, National Health and Nutrition Examination Survey 2007 to 2012. 2015;103(6):517-26.

11. Murray CJ, Lopez AD. Regional patterns of disability-free life expectancy and disability-adjusted life expectancy: global Burden of Disease Study. Lancet. 1997;349(9062):1347-52.

12. Moussa HN, Hosseini Nasab S, Haidar ZA, Blackwell SC, Sibai BM. Folic acid supplementation: what is new? Fetal, obstetric, long-term benefits and risks. Future Sci OA. 2016;2(2):FSO116.

13. Williams PA, Poehlman J, Moran K, Siddiqui M, Kataria I, Rego AM, et al. Strategies to address anaemia among pregnant and lactating women in India: a formative research study. Public Health Nutr. 2020;23(5):795-805.

14. Barchitta M, Maugeri A, Magnano San Lio R, Favara G, La Mastra C, La Rosa MC, et al. Dietary Folate Intake and Folic Acid Supplements among Pregnant Women from Southern Italy: Evidence from the "Mamma \& Bambino" Cohort. Int J Environ Res Public Health. 2020;17(2).

15. Bodnar LM, Himes KP, Venkataramanan R, Chen JY, Evans RW, Meyer JL, et al. Maternal serum folate species in early pregnancy and risk of preterm birth. Am J Clin Nutr. 2010;92(4):864-71.

16. Jankovic-Karasoulos T, Furness DL, Leemaqz SY, Dekker GA, Grzeskowiak LE, Grieger JA, et al. Maternal folate, one-carbon metabolism and pregnancy outcomes. Matern Child Nutr. 2020:e13064.

17. Dunlop AL, Taylor RN, Tangpricha V, Fortunato S, Menon R. Maternal micronutrient status and preterm versus term birth for black and white US women. Reprod Sci. 2012;19(9):939-48.

18. Shaw GM, Carmichael SL, Yang W, Siega-Riz AM, National Birth Defects Prevention S. Periconceptional intake of folic acid and food folate and risks of preterm delivery. Am J Perinatol. 2011;28(10):747-52.

19. Zou R, El Marroun H, Cecil C, Jaddoe V, Hillegers M, Tiemeier H, et al. Maternal folate levels during pregnancy and offspring brain development in late childhood. 2020.

20. Herter-Aeberli I, Wehrli N, Bärlocher K, Andersson M, Sych JJN. Inadequate Status and Low Awareness of Folate in Switzerland-A Call to Strengthen Public Health Measures to Ensure Sufficient Intakes. 2020;12(12).

21. de Benoist B. Conclusions of a WHO Technical Consultation on folate and vitamin B12 deficiencies. Food Nutr Bull. 2008;29(2 Suppl):S238-44.

22. Devakumar D, Kular D, Shrestha B, Grijalva-Eternod C, Daniel R, Saville N, et al. Socioeconomic determinants of growth in a longitudinal study in Nepal. 2018;14(1).

23. He Z, Bishwajit G, Yaya S, Cheng Z, Zou D, Zhou Y. Prevalence of low birth weight and its association with maternal body weight status in selected countries in Africa: a cross-sectional study. BMJ Open. 2018;8(8):e020410. 
24. Kastro S, Demissie T, Yohannes B. Low birth weight among term newborns in Wolaita Sodo town, South Ethiopia: a facility based cross-sectional study. BMC Pregnancy Childbirth. 2018;18(1):160.

25. Tafere TE, Afework MF, Yalew AW. Providers adherence to essential contents of antenatal care services increases birth weight in Bahir Dar City Administration, north West Ethiopia: a prospective follow up study. Reprod Health. 2018;15(1):163.

26. Kumlachew W, Tezera N, Endalamaw A. Below normal birth weight in the Northwest part of Ethiopia. BMC Res Notes. 2018;11(1):611.

27. Hailu L, Kebede DJBri. Determinants of Low Birth Weight among Deliveries at a Referral Hospital in Northern Ethiopia. 2018;2018:8169615.

28. Mingude AB, Gebretsadik W, Misker D, Woldeamanuel GG. Determinants of low birth weight among live birth newborns delivered at public hospitals in Gamo Gofa Zone, South Ethiopia: Unmatched case control study. SAGE Open Med. 2020;8:2050312120940544.

29. Asmare G, Berhan N, Berhanu M, Alebel AJBrn. Determinants of low birth weight among neonates born in Amhara Regional State Referral Hospitals of Ethiopia: unmatched case control study. 2018;11(1):447.

30. Bekela MB, Shimbre MS, Gebabo TF, Geta MB, Tonga AT, Zeleke EA, et al. Determinants of Low Birth Weight among Newborns Delivered at Public Hospitals in Sidama Zone, South Ethiopia: Unmatched Case-Control Study. J Pregnancy. 2020;2020:4675701.

31. Feresu SA, Harlow SD, Woelk GB. Risk Factors for Low Birthweight in Zimbabwean Women: A Secondary Data Analysis. PLoS One. 2015;10(6):e0129705.

32. Martin J, Hamilton B, Osterman MJNdb. Births in the United States, 2019. 2020(387):1-8.

33. Zhang B, Shang S, Li S, Mi B, Li M, Shi G, et al. Maternal folic acid supplementation and more prominent birth weight gain in twin birth compared with singleton birth: a cross-sectional study in northwest China. Public Health Nutr. 2020;23(16):2973-82.

34. Pathirathna M, Wimalasiri K, Sekijima K, Sadakata MJN. Maternal Compliance to Recommended Iron and Folic Acid Supplementation in Pregnancy, Sri Lanka: A Hospital-Based Cross-Sectional Study. 2020;12(11).

35. Zhang B, Shang S, Li S, Mi B, Li M, Shi G, et al. Maternal folic acid supplementation and more prominent birth weight gain in twin birth compared with singleton birth: a cross-sectional study in northwest China. 2020;23(16):2973-82.

36. Cross J, Jarjou O, Mohammed N, Rayment Gomez S, Touray B, Prentice A, et al. Early postnatal hypoferremia in low birthweight and preterm babies: A prospective cohort study in hospital-delivered Gambian neonates. 2020;52:102613.

37. Miranda-Hernández D, Sánchez A, Sánchez-Briones R, Rivas-Ruiz R, Cruz-Reynoso L, Cruz-Domínguez $P$, et al. Impact of Systemic Lupus Erythematosus on Pregnancy: Analysis of a Large 10-Year Longitudinal Mexican Cohort. 2020.

38. Bhaskar RK, Deo KK, Neupane U, Chaudhary Bhaskar S, Yadav BK, Pokharel HP, et al. A Case Control Study on Risk Factors Associated with Low Birth Weight Babies in Eastern Nepal. Int J Pediatr. 
2015;2015:807373.

39. Hay G, Clausen T, Whitelaw A, Trygg K, Johnston C, Henriksen T, et al. Maternal folate and cobalamin status predicts vitamin status in newborns and 6-month-old infants. J Nutr. 2010;140(3):557-64.

40. Azzini E, Ruggeri S, Polito AJljoms. Homocysteine: Its Possible Emerging Role in At-Risk Population Groups. 2020;21(4).

41. Fayehun O, Asa SJPo. Abnormal birth weight in urban Nigeria: An examination of related factors. 2020;15(11):e0242796.

42. Assari SJRihs. Protective Effects of Maternal Education against Low Birth Weight Deliveries: Blacks' Diminished Returns. 2020;5(4):1-17.

43. Domanski G, Lange AE, Ittermann T, Fallenberg J, Allenberg H, Zygmunt M, et al. Maternal prepregnancy underweight as a risk factor for the offspring: Survey of Neonates in Pomerania. Acta Paediatr. 2020. 